\title{
ADSORPTION OF HYDROPHOBICALLY MODIFIED POIYELECTROIYTES ON HYDROPHOBIC SUBSTRATES
}

\section{Y. ZHANG and M. TIRRELL}

University of Minnesotal

\section{J.W. MAYS}

University of Alabama²

(1) Department of Chemical Engineering and Materials Sclence Minneapolis, MN55455

(2) Department of Chemistry, Birmingham, Alabama 35294

\section{ADSORPTION DE POLYÉLECTROLYTES MODIFIÉS HYDROPHOBIQUEMENT SUR LES SUBSTRATS HYDROPHOBES}

Une série de copolymères à diblocs poly (tert-butyle styrène)-sodium (sulfonate de polystyrène) de masses moléculaires et pourcentages de sulfonation différents ont été utilisés pour étudier les effets de la structure du polymère sur son pouvoir d'adsorption sur des surfaces de silicium modifiées hydrophobiquement. Le pourcentage du bloc hydrophobe varie de 3,6 à $8,9 \%$. Les études antérieures montrent que la concentration saline est très importante pour l'adsorption de ces polyélectrolytes sur les surfaces de silice. Nous avons utilisé l'octadecyltriéthoxysilane (OTE) pour modifier la surface de silicium qui change l'angle de contact de l'eau de $50^{\circ}$ sur la silice non modjfiée à une valeur comprise entre $100^{\circ}$ et $120^{\circ}$ sur la silice modifiée. Sur cette surface hydrophobe, nous constatons que l'adsorption de ces polyélectrolytes légèrement modifiès hydrophobiquement est proche de la loi puissance $4 / 23$ avec la concentration saline prédite par un modèle récent. La densité d'implantation est également cohérente avec une cépendance à la longueur du bloc hydrophobe à la puissance $-12 / 23$, et à la longueur du bloc polyélectrolyte à la puissance $-6 / 23$ prédite par ce modèle.

\section{ADSORPTION OF HYDROPHOBICALLY MODIFIED POLYELECTROLYTES ON HYDROPHOBIC SUBSTRATES}

A series of diblock copolymers, poly (tert-butyl styrene)-sodium poly (styrene sulfonate) with different molecular weight and percentage of sulfonation have been used to study the effect of polymer structure on its adsorption behavior onto hydrophobically modified silicon wafers. The percentage of the hydrophobic block varies from $3.6-8.9 \%$. Previous studies show that salt concentration is very important for the adsorption of such polyelectrolytes onto silica surfaces. Octadecyltriethoxysilane (OTE) has been used to modify the silicon wafer which changes the water contact angle from $50^{\circ}$ on unmodified silica to $100^{\circ}$ to $120^{\circ}$. On this hydrophobic surface, we found that the adsorption of these slightly hydrophobically modified polyelectrolytes is close to the $4 / 23$ rd power of salt concentration predicted by a recent model. The grafting density is also consistent with a dependence on the length of the hydrophobic block to the -12/23rd power, and the length of the polyelectrolyte block to the $-6 / 23 r d$ power, predicted by this model. 
ADSORCIÓN DE POLIELECTROLITOS MODIFICADOS HIDROFÓBICAMENTE SOBRE LOS SUSTRATOS HIDRÓFOBOS

Se ha utilizado una serie de copolímeros de dibloques poli (tertbutilo-estireno)-sodio (sulfonato de poliestireno) de distintas masas moleculares y porcentajes de sulfonación, para estudiar los efectos de la estructura del polímero sobre su poder de adsorción sobre las superficies del sílicio modificadas hidrofóbicamente. El porcentaje del bloque hidrófobo oscila entre 3,6 y $8,9 \%$. Diversos estudios anteriores vienen a demostrar que la concentración salina es sumamente importante para la adsorción de estos polielectrolitos sobre las superficies de sílice. Se ha utilizado el octadeciltriehosisilano (OTE) para modificar la superficie de sílicio que modifica el ángulo de contacto del agua de $50^{\circ}$ sobre la sílice no modificada a un valor que oscila entre $100^{\circ}$ y $120^{\circ}$ sobre la sílice modificada. Se comprueba así, que sobre esta superficie hidrófoba, la adsorción de estos polielectrolitos ligeramente modificados hidrofóbicamente es cercana de la ley de potencia 4/23 con la concentración salina contemplada por un modelo reciente. La densidad de implantación guarda también coherencia con una dependencia respecto a la longitud del bloque hidrófobo a la potencia $-12 / 23$ y a la longitud del bloque polielectrolito a la potencia $-6 / 23$ contemplada por este modelo.

\section{INTRODUCTION}

Polymeric amphiphiles are important in manipulation of the physical and chemical interactions between surfaces and their surroundings. While the insoluble block acts as anchor to create layers of polymer on substrate, the soluble block confers useful properties on the solid interfaces. Polyelectrolytes with a nonsoluble block, which we term "hydrophobically modified polyelectrolytes" here, introduce long-ranged electrostatic interactions in addition to specific interactions and steric repulsion in aqueous systems. Efforts have been made to understand the factors governing the assembly and behavior of hydrophobically modified polyelectrolytes.

In our previous study on silicon wafers with a thick thermally grown $\mathrm{SiO}_{2}$ layer [1], the adsorption of hydrophobically modified polyelectrolytes were found to be controlled by the amount of extra salt added. Below a certain ionic strength, there is no adsorption observed and above a certain salt concentration, the adsorption increases with more salt which was explained by the screening of the strong electrostatic interactions and the concommitant reduction of the penalty for assembling a dense polyelectrolyte layer [1]. In this paper, we discuss the adsorption behavior of the polyelectrolytes onto a surface more hydrophobic than silica.

\section{EXPERIMENTAL SECTION}

\subsection{Materials}

The length of each block as well as the percentage of sulfonation of the hydrophilic block is listed in Table 1. Solution preparation and data analysis have been discussed in detail in a previous paper [2].

\subsection{OTE Deposition}

The silicon substrates were 1.25-2" one side polished $\mathrm{N}$ type silicon wafers (100 surfaces) from Virginia Semiconductor Co. The wafers were soaked in a 3:7 hydrogen peroxide/sulfuric acid solution for 5 minutes and rinsed in deionized water for five minutes before put in a UV lamp for 15 minutes. The octadecyltriethoxysilane was first hydrolysed for 2 hours in the following solution: $92 \mu \mathrm{l}$ OTE, $54 \mu \mathrm{l} 1.31 \mathrm{~N} \mathrm{HCl}$, diluted to $10 \mathrm{ml}$ by THF. Then the hydrolysed OTE was diluted 20 times by cyclohexane. Wafer fresh from the 
UV lamp was dipped immediately into the solution and stay there for 1 hour. After the deposition, the silicon wafer was baked at $120^{\circ} \mathrm{C}$ for 2 hours [3].

TABLE 1

Molecular information of MT series of polyelectrolytes

\begin{tabular}{l|r|r|r|r|r}
\hline & MT7 & MT2 & MT5 & MT3 & \multicolumn{1}{c}{ MT1 } \\
\hline $\mathrm{M}_{w}$ & 24.000 & 83.000 & 86.000 & 150.000 & 180.000 \\
\hline PtBs & 4 & 26 & 15 & 27 & 56 \\
\hline NaPSS & 128 & 403 & 438 & 757 & 869 \\
\hline \% Sulfonation & 78 & 89 & 85 & 87 & 93 \\
\hline
\end{tabular}

\section{RESULTS AND DISCUSSIONS}

We compare our data with the results of two scaling models. There are other models of block copolyelectrolyte adsorption, but the conditions do not correspond our experimental system $[4,5,6]$.

We start by briefly reviewing the main arguments of the two models. In the following discussions, $\mathrm{N}_{\mathrm{A}}$ is the number of segment of the anchoring block, that is, the hydrophobic block and $\mathrm{N}_{\mathrm{p}}$ is the number of segment of the polyelectrolyte block. $[\mathrm{NaCl}]$ represents the molar concentration of sodium chloride in the system. $\mathrm{F}$ is the charge density along the chain.

Dan and Tirrell [7] (DT) considered the adsorption of hydrophobically modified, fully charged polyelectrolytes by scaling. Several regimes were considered, we only discuss the van der Waals regime that fits our data the best. The non-adsorbing polyelectrolytes chain is envisioned as a succession of "blobs". A blob is defined as an object within which excluded yolume effects dominate and outside of which excluded volume are screened, which means that chains of blobs are Gaussian. Only the case that correlation length of a blob is larger than the chain persistence length is considered. That is, the chains exhibit excluded volume behavior. A blob is then envisioned as composed of a series of rodlike segments, the length of which is determined by the persistence length. Therefore, the correlation length of a blob is determined by the persistence length of polyelectrolyte and the polymer segment concentration. Since the persistence length of polyelectrolyte is determined by salt concentration, the correlation length of a blob scales with the salt concentration and polymer concentration. The chain extension in the layer is determined by the number of blobs per chain, and the free energy of the charged chain is determined by assuming each blob comprises a free energy of order kT. The adsorbed amount was treated as controlled by the van der Waals attraction of the film with the absorbing surface, and the stretching free energy of the charged brush. The van der Waals attraction is a function of the grafting density and NA as they determine the anchoring film thickness. In the limit of strong attraction, the adsorbed amount was found to be proportional to $\mathrm{N}_{\mathrm{A}}{ }^{-12 / 23} \mathrm{~N}_{\mathrm{P}}{ }^{-6 / 23}[\mathrm{NaCl}]^{4 / 23}$.

Israels, Scheutjens and Fleer [8] (ISF) considered the adsorption of hydrophobically modified polyelectrolytes at high and low anchor density regimes. The high anchor density part does not fit our data at all. So we will only discuss the low anchor density scaling which also turns out inappropriate but may shed some light on understanding the adsorption behavior of our system. A less-than-monolayer coverage was assumed. That is, there is no interaction among the adsorbed polyelectrolyte chains. In this case, the chain extension is determined by balancing the osmotic pressure with the elastic energy per unit area. This results in the chain extension as a function of the grafting density and the polyelectrolyte length. The energy of the adsorbed layer in this low anchor density regime is approximated as consisting of adsorption.energy contributions only and a Flory-Huggins interaction parameter between anchoring block and the adsorbent is used. By minimizing the energy of the adsorbed layer and the elastic energy of the polyelectrolyte brush with regard to the grafting density, another expression for polyelectrolyte extension is achieved. Equating the two expressions for the brush length, the adsorbed amount scales as $\left(\mathrm{N}_{\mathrm{A}} / \mathrm{N}_{\mathrm{P}}\right)^{3 / 2}[\mathrm{NaCl}] \mathrm{F}^{-2}$.

\section{EFFECT OF IONIC STRENGTH}

The concentration of $\mathrm{NaCl}$, which determines the electrostatic screening effect, was in the range of 0 to $1 \mathrm{M}$. The corresponding adsorbed amounts and curve fits are shown in Figure 1 (polymer concentration is $0.0625 \mathrm{mg} / \mathrm{ml}$ ).

As we fit the adsorbed amount to the power law of salt concentration at $4 / 23$, the fitting curve matches the experimental data of MT3 and MT5 well. But when 
a.

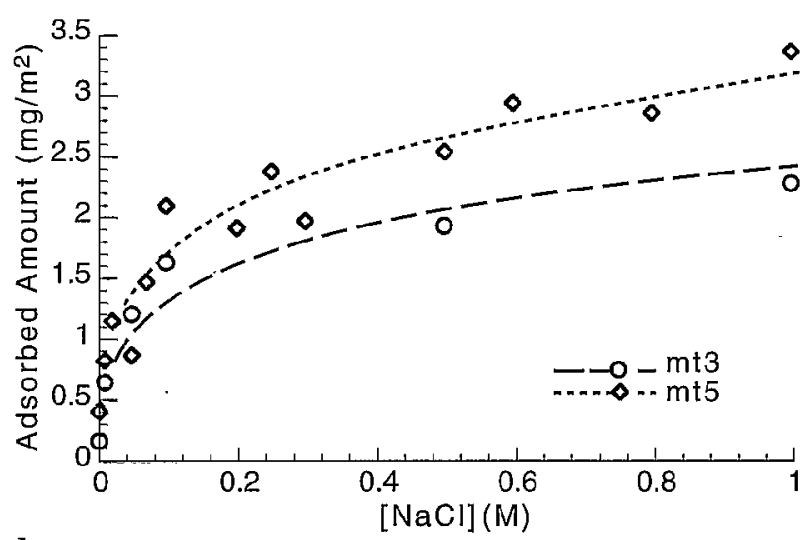

b.

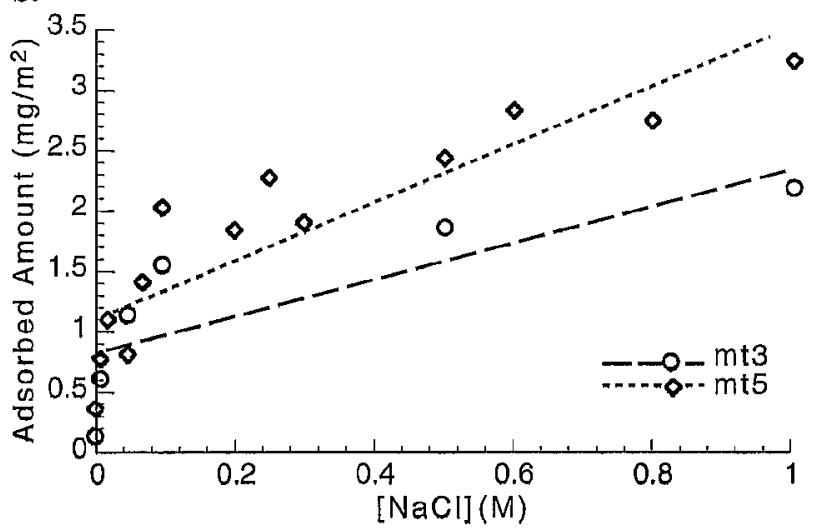

Figure 1

Effect of $\mathrm{NaCl}$ concentration. a, curve fit as $[\mathrm{NaCl}]^{4 / 23}$ according to the DT scaling result; $b$, curve fit as $[\mathrm{NaCl}]$ according to the ISF scaling result.

we increase the power to 1 , the curve doesn't fit the low salt region at all. Neither does it fit the high salt region well. The $\mathrm{NaCl}$ effect considered in these models are basically on the free energy of the polyelectrolyte brush, which comes from screening that reduces the elastic energy of the brush. The reason that the ISF model does not fit well is mainly that the anchoring density was treated as very low so that there is no interaction among chains. This assumption leads to the simplification that the elastic energy of a chain is not effected by the graf. ting density. This might be true in case of extremely low grafting density. In our case, the adsorbed amount is high enough to allow interactions among chains and cause them to stretch further even though itis not high enough to fit the high grafting density regime in ISF's scaling, The difference in scaling result comes from the treatment of the effect of grafting density on the free energy of the system. Even so, it is clear from both models that the role of salt is mainly to reduce the repulsion among polyelectrolyte chains and segments to reduce the elastic stretching energy of the chain.

\section{EFFECT OF MOLECULAR STRUCTURE}

We plot our data according to the scaling results of the DT model and the ISF model. Figure $2 \mathrm{a}$ is the grafting density versus $N_{A}^{-12 / 23} N_{P}^{-6 / 23}$ based on DT's model. Figure $2 b$ is the grafting density versus $\mathrm{N}_{\mathrm{A}}{ }^{-12 / 23} \mathrm{~N}_{\mathrm{P}}{ }^{-6 / 23}[\mathrm{NaCl}]^{4 / 23}$. Figure 3 is plotted according to the scaling of ISF.

The essential difference between the two models is the assumption about the adsorbed density. The DT model assumes a high anchoring density, which leads to the van der Waals attraction being strong and a function of the grafting density and the length of the anchoring block. In this case, the length of the anchoring block reduces the attraction force by increasing the film thickness. The adsorbed amount works in the same sense. The more polymer adsorbed, the thicker the film, the smaller the attraction. When the assumption turns to low anchor density, however, the function of hydrophobic block and grafting density changes. When the grafting density is low, the attraction per chain is proportional to the number of segments in the anchoring block. These assumptions lead to the difference in the effect of the length of each block as well as salt concentration.

In our system, OTE is the absorbing substrate, which has contact angle with water of $120^{\circ}$ when the film is a perfect monolayer. Since our anchoring PtBS block is not water soluble, there is strong attraction between the surface and the anchoring block. Even though the hydrophobic blocks are not overlapping in average according to the adsorbed amount which makes the expression for van der Waals force seemingly not applicable, considering the adsorbed species as piecewise layers, or adsorbed hemimicelles, instead of uniformly distributed chains may account for the good fit of the DT model. Locally, the adsorbed chains have their anchoring blocks strongly overlapped with each other. Within such a small cluster, the thickness of the anchoring film is proportional to the length of the anchoring block and the number of chains in the cluster, which is proportional to the adsorbed amount. Figure 2a shows that at each salt concentration, namely 


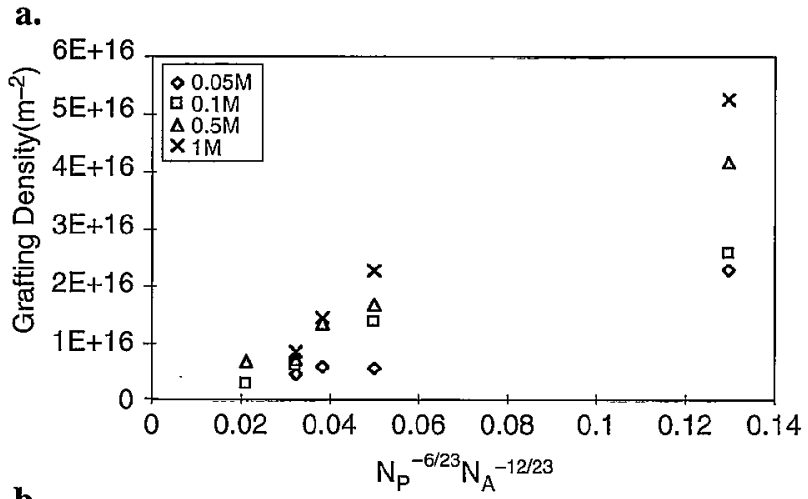

$$
\text { b. }
$$

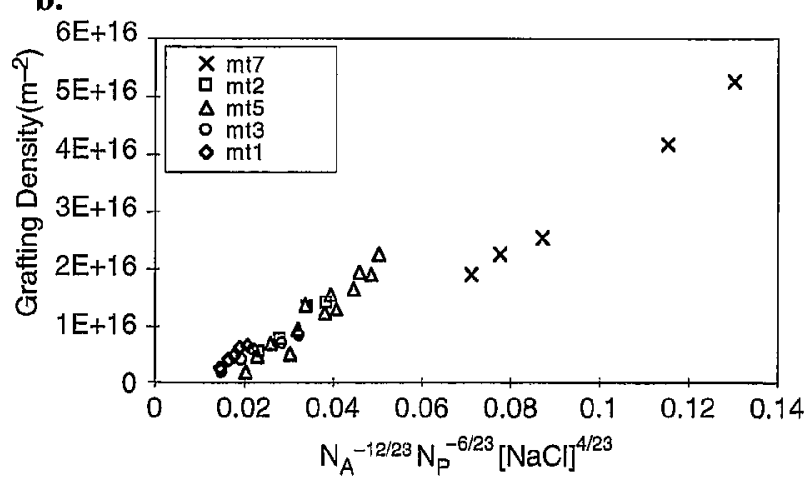

Figure 2

Grafting density versus polymer structure according to DT scaling.
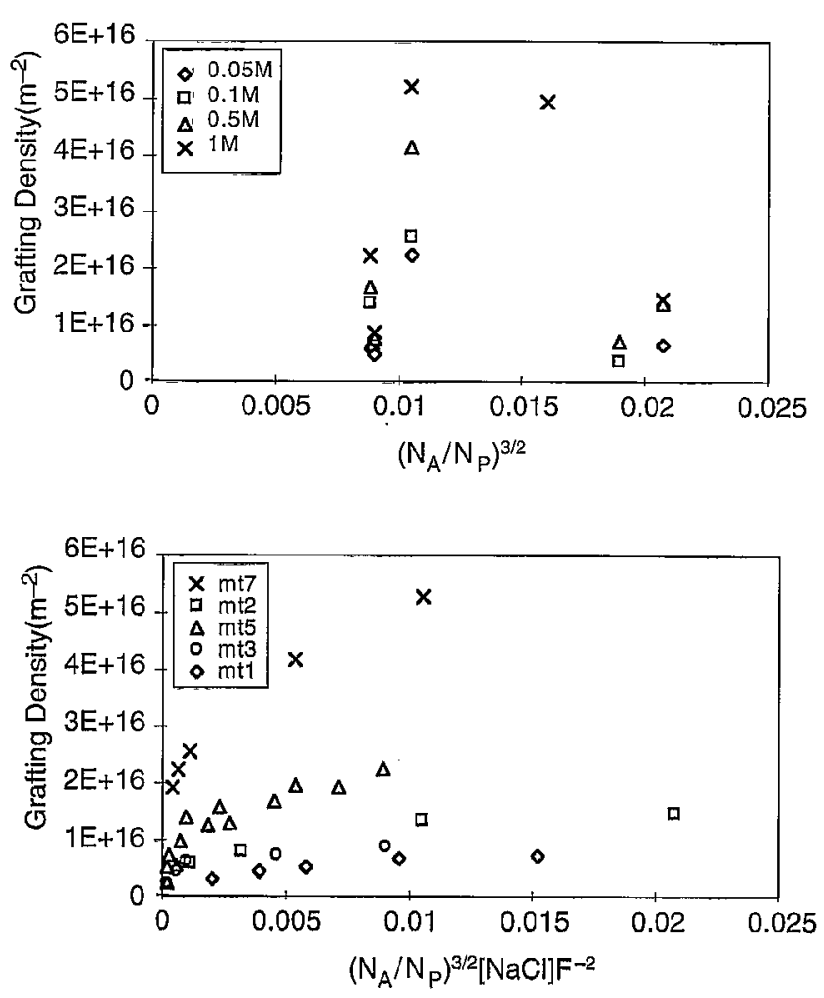

Figure 3

Grafting density versus polymer structure according to ISF scaling.

the osmotic pressure and elastic energy. The adsorbed amount depends on salt concentration to 4/23rd power. Increasing the size of either block causes the decrease of adsorbed amount. Dependence on the size of the hydrophobic block is stronger.

\section{REFERENCES}

1 Zhang Y., Tirrell, M. and J, Mays (1996), Macromolecules, 29, p. 7299.

2 Amiel C., Sikka, M., Schneider, J.W., Tsao, Y., Tirrell, M. and J. Mays (1995), Macromolecules, 28, p. 3125.

3 Frantz P, and S. Granick (1992), Langmuir, 8, p. 1176.

4 Joanny J,F, and, L, Leibler (1990), J. Phys. France, 51, p. 545.

5 Shubin V., Langmuir (1994), 10, p. 1093.

6 Wittmer J, and J.F, Joanny (1993), Macromolecules, 26, p. 2691.

7 Dan N. and M. Tirrell (1993), Macromolecules, 26, p. 4310.

8 Israels R., J.M.H.M. Scheutjens and G.J. Fleer (1993), Macromolecules, 26, p. 5405.

Final manuscript recelved in January 1997 